\title{
Risk Factors and Prognosis of Nontuberculous Mycobacteria Infection in a High Prevalence of Tuberculosis Setting
}

\author{
Leli Saptawati1,2,3), Yusuf Ari Mashuri4), Betty Suryawati'), \\ Harsono5), Riska Pradiptakirana ${ }^{6)}$ \\ ${ }^{1)}$ Department of Microbiology, Faculty of Medicine, Universitas Sebelas Maret, Indonesia \\ 2)Department of Microbiology, Moewardi Teaching Hospital, Surakarta, Indonesia \\ 3)Doctorate Program of Medical Science, Universitas Sebelas Maret, Indonesia \\ 4)Department of Parasitology, Faculty of Medicine, Universitas Sebelas Maret, Indonesia \\ 5)Center for Community Lung Health, Surakarta, Indonesia \\ ${ }^{6)}$ Medicine Undergraduate Program, Faculty of Medicine, Universitas Sebelas Maret, Indonesia
}

\section{ABSTRACT}

Background:The prevalence and incidence of Nontuberculous Mycobacteria (NTM) infections in the world in general have continued to increase in the last two to three decades. Until now identification and testing of NTM sensitivity in Indonesia is still very difficult to do in daily health services. Thus, NTM infection is still a neglected case and misdiagnosis often occurs. In these conditions, one of the things that is very important to help clinicians in the management of NTM infections is information about patient characteristics and how the relationship of risk factors for NTM infection with prognosis.

Subjects and Method: The study was conducted retrospectively using data on the medical records of patients with positive culture of NTM at the Surakarta Center for Community Lung Health (BBKPM) for 3 years (2016-2018). A total of 134 samples were selected for this study with total sampling. The dependent variable is the prognosis of infection. The independent variables were gender, age, occupation, history of inhaled corticosteroid use, antibiotic therapy, and underlying disease. Data were analyzed using multiple logistic regression.

Results: The number of samples is 143 medical records. Most of the patients in this study were male $(62.90 \%)$ and aged less than 60 years (79.70\%). The majority of patients work not as farmers (80.40\%). Most patients had no history of inhaled corticosteroid use (89.50\%). Therapeutic factors indicate that the majority of patients receive combined antibiotic therapy (68.5\%). As many as $42 \%$ of patients with NTM infection have an underlying disease. Underlying disease in patients is mostly in the form of diabetes mellitus (DM) in $13.3 \%$ and in the former tuberculosis in $4.9 \%$. Based on the Chi-Square test, a significant relationship was found between therapeutic factors, history of inhaled corticosteroid use, and type of work, and the patient's prognosis. Based on multivariable testing, the factor of antibiotic therapy is the most influential variable on a patient's prognosis.

Conclusion: Risk factors related to the patient's prognosis are occupation, use of inhaled corticosteroids and antibiotic therapy.

Keywords: Nontuberculous Mycobacteria, risk factors, prognosis, Center for Community Lung Health

\section{Correspondence:}

Leli Saptawati. Department of Microbiology, Faculty of Medicine, Universitas Sebelas Maret, Indonesia. Jl. Ir. Soetami no. 36A Kentingan Surakarta, Indonesia.Email: llsapt_md@yahoo.co.id. Mobile: (0271) 632489.

Cite this as:

Saptawati L, Mashuri YA, Suryawati B, Harsono, Pradiptakirana R (2020). Risk Factors and Prognosis of Nontuberculous Mycobacteria Infection in a High Prevalence of Tuberculosis Setting. J Epidemiol Public Healt. 5(1): 79-87. https://doi.org/10.26911/jepublichealth.2020.05.01.08

cc (i) (-) Journal of Epidemiology and Public Healthis licensed under a Creative Commons

EY NC SA Attribution-NonCommercial-ShareAlike 4.0 International License. 


\section{BACKGROUND}

Nontuberculous Mycobacteria (NTM) or Mycobacteria Other Than Tuberculosis (MoTT) are Mycobacteria that do not cause tuberculosis (TB) and leprosy infections (Johnson and Odell, 2014). This bacteria easily transmitted through water and air. Chronic pulmonary disease is the most common clinical manifestation (65-90\%) (Stout et al., 2016; Juita and Fauzar, 2018). The prevalence and incidence of NTM infections in the world in general have continued to increase in the last two to three decades.

The results of studies in South Korea mention the prevalence and incidence of NTM continues to increase from 2007 to 2016. In 2016, there were 39.60 cases per 100,000 population with an annual incidence of 19.00 cases per 100,000 population (Lee et al., 2019). A Japanese study reported an increase in the incidence of NTM infection from 5.7 cases per 100,000 people per year in 2007 to 14.7 cases per 100,000 people per year in 2015 (Namkoong et al., 2016). The prevalence of NTM in Surakarta, Central Java, Indonesia, which has been studied for 5 years (2013-2017) is $15.00 \%$ (334/2226 positive culture of Mycobacteria) (Saptawati et al., 2019).

Until now, identification and sensitivity testing of NTM in Indonesia is still very difficult to do in daily health services. Lung disease by NTM also has symptoms similar to pulmonary tuberculosis (Liao et al., 2016). In these conditions, one of the most important things to help clinicians diagnose NTM infection is information about the characteristics of patients who are risk factors and how these risk factors relate to the prognosis of NTM infection. Until now, in Indonesia there is no scientific data on this matter. Thus, research needs to be conducted that aims to determine the characteristics of patients who are associated with the risk of NTM infection and prognosis.

\section{SUBJECTS AND METHOD}

\section{Study Design}

This wasa cross-sectional study conducted in June - August 2019 using secondary data in the form of patient medical records. The study was carried out at the Surakarta Center for Community Lung Health (BBKPM).

\section{Population dan Sample}

The population in this study were all medical records of patients with positive culture results of NTM infection in BBKPM Surakarta for 3 years (2016-2018). The sampling was done using total sampling technique. The number of samples obtained was 134 .

\section{Study Variables}

The dependent variable is the prognosis of infection. The independent variables were gender, age, occupation, history of inhaled corticosteroid use, antibiotic therapy, and underlying disease.

\section{Operational Definition of Variables}

Age is grouped into the elderly ( $>60$ years) and not the elderly (less than 60 years).

Occupation is farmers (close contact with the land) and not farmers.

The use of inhaled corticosteroid is classified as yes and no.

Antibiotic therapy is grouped into 3 namely without antibiotics, with a single antibiotic and with a combination antibiotic. Careful underlying diseases include chronic obstructive pulmonary disease (COPD), bronchiectasis, asthma, diabetes mellitus (DM), HIV, and ex-tuberculosis (TB).

Underlying disease can be divided into four categories, namely without underlying disasters, with one type of underlying disasters, with two types of underlying disasters and more than two types of underlying disasters.

The patient's prognosis is differentiated into healed and not cured. It is said to be cured when the doctor who treats the patient states that heal is supported by examination of sputum culture. It is said not to recover if 
the patient dies, is referred to another hospital or does not continue treatment for no apparent reason.

\section{Data Analysis}

The data obtained were analyzed by univariate, bivariate, and multivariate tests. The statistical test used was Chi-Square and multiple logistic regression.

\section{Research Ethic}

Research ethical issues including anonymity and confidentiality, were addressed carefully during the study process. The research ethical clearance approval letter was obtained from the Research Ethics Committee at Universitas Sebelas Maret, Indonesia, No. 264/UN27.06/KEPK/EC/2019, on July 24, 2019.

\section{RESULTS}

\section{Sample Characteristics}

In this study, 155 samples of medical records from patients with positive culture were obtained in NTM, of which 12 of them could not be further investigated because the medical record file could not be found. Characteristics of the sample can be seen in Table 1 .

Table 1. Sample characteristics

\begin{tabular}{llcc}
\hline Characteristics & \multicolumn{1}{c}{ Category } & Frequency & Percentage \\
\hline \multirow{2}{*}{ Gender } & Male & 90 & $62.9 \%$ \\
Age & Female & 53 & $37.1 \%$ \\
\multirow{2}{*}{ Occupation } & $<60$ years old & 4 & $79.7 \%$ \\
Inhaled corticosteroids & $\geq 60$ years old & 18 & $20.3 \%$ \\
& Farmer & 28 & $19.6 \%$ \\
Underlying disease & Non farmer & 115 & $80.4 \%$ \\
& No & 15 & $10.5 \%$ \\
& Nothing & 128 & $89.5 \%$ \\
& One type & 83 & $58.0 \%$ \\
Antibiotic therapy & Two types & 41 & $28.7 \%$ \\
& More than two types & 14 & $9.8 \%$ \\
& Without antibiotics & 5 & $3.5 \%$ \\
Prognosis & One antibiotics & 16 & $20.3 \%$ \\
& Antibiotics combination & 98 & $11.2 \%$ \\
& Recovered & 63 & $68.5 \%$ \\
\hline
\end{tabular}

Based on the results of univariate analysis obtained data that the majority of patients were male sex amounted to $62.9 \%$ and most aged $<60$ years which amounted to $79.7 \%$. As many as $80.4 \%$ of patients work as farmers and $42 \%$ of patients with NTM infection have an underlying disease. The distribution of types of underlying disease can be seen in table 2. Most of the patients received combined antibiotic therapy that is as much as $68.5 \%$. The use of inhaled corticosteroids is found in $10.5 \%$ of patients. 
Saptawati et al./Risk Factors and Prognosis of Nontuberculous Mycobacteria Infection

Table 2. Distribution of types of underlying disease

\begin{tabular}{|c|c|c|c|}
\hline Underlying diseases & Category & $\mathbf{n}$ & Percentage \\
\hline Nothing & & 83 & $58 \%$ \\
\hline \multirow{8}{*}{ One type } & $\begin{array}{l}\text { Chronic obstructive } \\
\text { disease (COPD) }\end{array}$ & 3 & $2.1 \%$ \\
\hline & Bronchiectasis & 3 & $2.1 \%$ \\
\hline & Asthma & 2 & $1.4 \%$ \\
\hline & Gastroesophageal reflux disease (GERD) & 3 & $2.1 \%$ \\
\hline & Cancer & $\mathrm{O}$ & $0 \%$ \\
\hline & HIV & 4 & $2.8 \%$ \\
\hline & $\mathrm{DM}$ & 19 & $13 \cdot 3 \%$ \\
\hline & TBC former & 7 & $4.9 \%$ \\
\hline \multirow{7}{*}{ Two types } & COPD, Bronchiectasis & 2 & $1.4 \%$ \\
\hline & GERD, TBC former & 2 & $1.4 \%$ \\
\hline & $\mathrm{HIV}, \mathrm{DM}$ & 1 & $0.7 \%$ \\
\hline & Bronchiectasis, TBC former & 3 & $2.1 \%$ \\
\hline & COPD, GERD & 1 & $0.7 \%$ \\
\hline & COPD, TBC former & 1 & $0.7 \%$ \\
\hline & DM, TBC former & 4 & $2.8 \%$ \\
\hline \multirow{5}{*}{$\begin{array}{l}\text { More than two } \\
\text { types }\end{array}$} & COPD, GERD, DM & 1 & $0.7 \%$ \\
\hline & COPD, Bronchiectasis, TBC former & 1 & $0.7 \%$ \\
\hline & COPD, Asthma, GERD, TBC former & 1 & $0.7 \%$ \\
\hline & $\begin{array}{l}\text { COPD, Bronchiectasis, Asthma, TBC } \\
\text { former }\end{array}$ & 1 & $0.7 \%$ \\
\hline & $\begin{array}{l}\text { COPD, Bronchiectasis, GERD, TBC } \\
\text { former }\end{array}$ & 1 & $0.7 \%$ \\
\hline
\end{tabular}

\section{Bivariate Analysis}

In the bivariate analysis, of the 143 medical record samples as many as 9 samples could not be analyzed because there was no information about the patient's prognosis, so that included in the analysis were 134 samples. The relationship between risk factors and prognosis can be seen in table 3 . Based on the results of calculations using the chi-square test it can be seen that there is no significant relationship between $\operatorname{sex}(\mathrm{p}=0.722)$, age $(\mathrm{p}=$ o.933), and underlying disease $(\mathrm{p}=0.876)$ with prognosis. There was a significant relationship between work ( $\mathrm{p}=0.025)$, use of inhaled corticosteroids $(\mathrm{p}=0.011)$ and antibiotic therapy $(\mathrm{p}=0.001)$ with prognosis. 
Saptawati et al./Risk Factors and Prognosis of Nontuberculous Mycobacteria Infection

Table 3. Relationship between risk factors and prognosis

\begin{tabular}{|c|c|c|c|c|c|}
\hline \multirow{3}{*}{ Variables } & \multicolumn{4}{|c|}{ Recovery } & \multirow{3}{*}{$\mathbf{p}$} \\
\hline & \multicolumn{2}{|c|}{ No } & \multicolumn{2}{|c|}{ Yes } & \\
\hline & $\mathbf{N}$ & $\%$ & $\mathbf{N}$ & $\%$ & \\
\hline \multicolumn{6}{|l|}{ Gender } \\
\hline Male & 46 & 54.8 & 38 & 45.2 & \multirow{2}{*}{0.722} \\
\hline Female & 25 & 50.0 & 25 & 50.0 & \\
\hline \multicolumn{6}{|l|}{ Age } \\
\hline$<60$ years old & 56 & 52.3 & 51 & $47 \cdot 7$ & \multirow{2}{*}{0.933} \\
\hline$\geq 60$ years old & 15 & 55.6 & 12 & 44.4 & \\
\hline \multicolumn{6}{|l|}{ Occupation } \\
\hline Farmer & 20 & 74.1 & 7 & $25 \cdot 9$ & \multirow{2}{*}{0.025} \\
\hline Not farmer & 51 & 47.7 & 56 & 52.3 & \\
\hline \multicolumn{6}{|l|}{ Underlying disease } \\
\hline Nothing & 39 & 50.0 & 39 & 50.0 & \multirow{4}{*}{0.876} \\
\hline One type & 21 & 56.8 & 16 & 43.2 & \\
\hline Two types & 8 & 57.1 & 6 & 42.9 & \\
\hline More than two types & 3 & 53.0 & 2 & 40.0 & \\
\hline \multicolumn{6}{|c|}{ Inhaled corticosteroids } \\
\hline Yes & 11 & 84.6 & 2 & 15.4 & \multirow[t]{2}{*}{0.011} \\
\hline No & 60 & 49.6 & 61 & 50.4 & \\
\hline \multicolumn{6}{|l|}{ Antibiotic therapy } \\
\hline No antibiotic & 20 & 95.2 & 1 & 4.8 & \multirow{3}{*}{$<0.001$} \\
\hline Single & 6 & 40.0 & 9 & 60.0 & \\
\hline Combination & 45 & 45.9 & 53 & 54.1 & \\
\hline
\end{tabular}

\section{Multivariate analysis}

Based on the results of multivariable analysis using multiple logistic regression with the enter method, it was found that the most dominant variable related to the patient's prognosis was antibiotic therapy with $\mathrm{p}=0.015$,
$\mathrm{OR}=18.93$ and $95 \% \mathrm{CI}=2.40-149.39$. The next variable is work with $\mathrm{p}=0.043, \mathrm{OR}=$ 02.85 and 95\% $\mathrm{CI}=1.03-7.83$. Meanwhile, the use of inhaled corticosteroids is a confounding variable. Multivariate analysis data can be seen in table 3 .

Table 4. Multivariate analysis

\begin{tabular}{lcccc}
\hline \multirow{2}{*}{ Independent Variables } & \multirow{2}{*}{ OR } & \multicolumn{2}{c}{$\mathbf{9 5 \%}$ CI } & \multirow{2}{*}{ p } \\
\cline { 3 - 4 } & & Lower limit & Upper limit & \\
\hline Occupation & 2.85 & 1.03 & 7.83 & 0.043 \\
Single antibiotics vs. & 18.93 & 2.39 & 149.39 & 0.015 \\
$\begin{array}{l}\text { combination antibiotics } \\
\text { No antibiotics vs. }\end{array}$ & 0.70 & 0.22 & 2.26 & \\
combined antibiotics & & & & \\
Inhaled corticosteroids & 4.07 & 0.79 & 21.04 & 0.094 \\
\hline
\end{tabular}




\section{DISCUSSION}

Based on univariate test results obtained data that the majority of patients were male (62.9\%). This is consistent with research on the characteristics of NTM patients in one of Singapore's hospitals which also showed that the majority of patients were male (62.1\%) (Lim et al., 2018). By age, the data of this study showed that the majority of patients were $<60$ years old $(79.7 \%)$ with the lowest age of 17 years. This is different from studies in Japan which show the average patient is aged $>70$ years (Hirose et al., 2019).

As many as $58 \%$ of patients without underlying disease. In patients with underlying disease most suffer from diabetes mellitus (DM) in the amount of $13.30 \%$ and former tuberculosis in the amount of $4.90 \%$. This is consistent with research in Singapore which shows that one third of the study population, amounting to $34.40 \%$, has a history of pulmonary tuberculosis (Lim et al., 2018)

In this study, risk factors significantly associated with prognosis are occupation, use of inhaled corticosteroids and antibiotic therapy. Antibiotic therapy is the most dominant factor influencing a patient's prognosis compared to other factors. Meanwhile factors not significantly related to the patient's prognosis are gender, age and underlying disease. Bivariate test results showed that there was no significant relationship between sex and prognosis $(\mathrm{p}=0.722)$.

This is not in accordance with Diel et al. (2018) who examined the death of pulmonary infection in NTM in five years. The results of the study showed that the mortality rate in five years was $25 \%$ greater in patients with male sex compared to women (Diel et al., 2018). The bivariate test results also showed that there was no significant relationship between age and prognosis $(\mathrm{p}=0.933)$. This is in contrast to research in Singapore which states that a worse prognosis occurs in patients with old age (Lim et al., 2018).
In this study, the test results showed that there was a significant relationship between work and prognosis $(\mathrm{p}=0.025)$ with an OR value of 2.85. Patients with NTM lung infections who work as farmers (in close contact with the soil) have a 2.85 times worse prognosis compared to non-farmers (not in close contact with the soil). That is because NTM is an opportunistic pathogen that is often found in the environment, especially in land and water. This is supported by one study that shows that patients with a history of high soil exposure are more at risk of infection with pulmonary disease by NTM namely Mycobacterium avium complex compared to controls $(23.60 \%$ compared to $9.40 \%, \mathrm{p}=0.032$ ) with multivariate analysis showing $\mathrm{OR}=5.90,95 \% \mathrm{CI}=1.4-24.7$ and $\mathrm{p}=$ 0.015. Land exposure is a risk factor for NTM lung infections (Maekawa et al., 2011).

In this study, the underlying diseases studied included chronic obstructive pulmonary disease (COPD), bronchiectasis, asthma, diabetes mellitus (DM), Human Immunodeficiency Virus (HIV) infection and former tuberculosis (TB). Bivariate test results showed that there was no significant relationship between underlying disease and prognosis $(\mathrm{p}=0.876)$.

This is not in accordance with the literature review conducted by Diel et al (2018). The study shows that patients with comorbidities (e.g. underlying lung disease) have a worse prognosis (Diel et al., 2018). Other research conducted on Ontarian states that COPD can increase the risk of developing lung disease by 9 times. In COPD pulmonary parenchymal destruction occurs, causing structural lung damage that will damage the pathogenic clearance mechanism (Marras et al., 2016).

The lower airway is normally sterile but in bronchiectasis conditions it is possible to colonize various microbes. Asthma is also one of the co-morbid factors that influence NTM 
infection. In asthma patients there is bronchial hyperresponsivity which can interfere with mucociliary cleansing which also complicates treatment (Marras et al., 2016).

Study in Taiwan showed that a previous history of tuberculosis was associated with a significantly increased risk of NTM disease $(\mathrm{OR}=5.58$ and $\mathrm{p}<0.001)$. Pulmonary disease NTM is also susceptible to developing in patients with HIV infection. This is due to the weakness of the body's defense system in HIV patients, which is characterized by a low $\mathrm{CD} 4$ cell count. The risk of infection is highest in patients with $\mathrm{CD} 4$ counts $<50$ cells / $\mathrm{mm}_{3}$ (Fitzpatrick et al., 2016). Chronic hyperglycemic conditions can cause oxidative stress, inflammation, and immune system dysfunction and thus contribute to infection (Baker et al., 2011).

Bivariate test results showed that there was a significant relationship between the use of inhaled corticosteroids and prognosis $(\mathrm{p}=$ o.011). In the multivariable test, the $\mathrm{OR}$ value $=4.07$ means that patients with NTM lung infection who use inhaled corticosteroid therapy have a prognosis 4.07 times worse than patients with NTM lung infection who do not consume inhaled corticosteroids.

This study is supported by Andréjak et al. (2013) which states that patients with chronic respiratory disease who receive inhaled corticosteroid therapy have a greater risk of getting pulmonary infection NTM 29.10x greater than patients who have never received inhaled corticosteroid therapy (Andréjak et al., 2013) Corticosteroids have the effect of lowering the body's immune system. Inhaled corticosteroids enter the lungs directly so that the lungs become vulnerable to infection (Brode et al., 2017). In studies conducted in mice, fluticasone inhaled corticosteroids damage the production of pulmonary macrophage cytokines and the synthesis of nitric oxide (Patterson et al., 2012). In addition, inhaled corticosteroids also reduce MALT cells that function as protection against mycobacterial infections (Hinks et al., 2016).

In this study, antibiotic therapy was also a risk factor that showed a significant relationship with prognosis $(\mathrm{p}<0.001)$. In multivariable testing, antibiotic therapy was the most dominant factor influencing the prognosis of patients with NTM infection ( $\mathrm{p}=$ o.015). Comparison between patients without antibiotics with patients receiving combination antibiotics obtained an $\mathrm{OR}=18.93$, while a comparison between single antibiotic therapy with a combination antibiotic obtained an $\mathrm{OR}=0.70$.

These results indicate that patients with NTM lung infection who did not receive antibiotic therapy had a prognosis 18.93 times worse than patients with NTM lung infection who received combination antibiotic therapy and patients with NTM lung infection who received single antibiotic therapy had a prognosis 0.70 times worse than patients with NTM lung infections receiving combination antibiotic therapy. The American Thoracic Society (ATS) in 2007 recommended combination therapy of macrolides (azithromycin or clarithromycin), rifampin or rifabutin with ethambutol with or without intravenous aminoglycosides (Griffith et al., 2007; Juita and Fauzar, 2018). In this study, $68.50 \%$ of patients received antibiotic therapy with macrolide (azithromycin or clarithromycin) rifampin or rifabutin and ethambutol with or without intravenous aminoglycosides, but $11.20 \%$ were still given single antibiotic therapy and as many as $\mathbf{2 0 . 3 0 \%}$ were not given antibiotics. Of all patients who did not receive antibiotics, as many as 20 patients (95.20\%) did not recover and only 1 patient (4.80\%) was declared cured.

From the results of this study it can be concluded that the risk factors associated with the patient's prognosis are occupation $(p=0.025)$, use of inhaled corticosteroids 
$(\mathrm{p}=0.011)$ and antibiotic therapy $(\mathrm{p}<0.001)$. Antibiotic therapy (a single antibiotic compared with a combination antibiotic) was the most significant variable affecting the patient's prognosis $(\mathrm{OR}=18.93$ and $95 \% \mathrm{CI}=$ 2.40 to $149.39 ; \mathrm{p}=0.015)$.

Limitations in this study are the number of samples that are too small for each type of risk factor so that further research needs to be done with a larger sample size for each type of risk factor.

\section{AUTHOR CONTRIBUTION}

Leli Saptawati, Yusuf Ari Mashuri, Betty Suryawati, Harsono, and Riska Pradiptakirana were collaborate equally to this study in developing the study idea, data searching, analysis study, and interpreting the results.

\section{CONFLICT OF INTEREST}

There is no conflict of interest in this study.

\section{FUNDING AND SPONSORSHIP}

Funds come from Non-tax revenue, Universitas Sebelas Maret in the 2019.

\section{ACKNOWLEDGEMENT}

We thank to hospital staff fromCenter for Community Lung Health Surakarta and medical students from Universitas Sebelas Maret for helping the data access.

\section{REFERENCE}

Andréjak C, Nielsen R, Thomsen VØ, Duhaut P, Sørensen HT, Thomsen RW (2013). Chronic respiratory disease, inhaled corticosteroids and risk of non-tuberculous mycobacteriosis. Thorax. 68(3): 256-62. doi: 10.1136/thoraxjnl-2012201772.

Baker RG, Hayden MS, Ghosh S (2011). NF$\kappa \mathrm{B}$, inflammation, and metabolic disease. Cell Metabolism, 13(1): 11-22. doi: 10.1016/j.cmet.2010.12.008.
Brode SK, Campitelli MA, Kwong JC, Lu H, Marchand-Austin A, Gershon AS, Jamieson FB, Marras TK (2017). The risk of mycobacterial infections associated with inhaled corticosteroid use. European Respiratory Journal, 5O(3): 1-10. doi: 10.1183/13993003.00037-2017.

Diel R, Lipman M, Hoefsloot W (2018). High mortality in patients with Mycobacterium avium complex lung disease: A systematic review. BMC Infectious Diseases. 18(1):206. doi: 10.1186/s12879018-3113-x.

Fitzpatrick M, Brooks JT, Kaplan JE (2016). Epidemiology of HIV-Associated Lung Disease in the United States. Semin Respir Crit Care Med, 37(02): 181-198. doi: 10.1055/s-0036-1572556.

Griffith DE, Aksamit T, Brown-Elliott BA, Catanzaro A, Daley C, Gordin F, Holland SM, Horsburgh R, et al. (2007). An official ATS/IDSA statement: Diagnosis, treatment, and prevention of nontuberculous mycobacterial diseases. American Journal of Respiratory and Critical Care Medicine, 175(4): 367416. doi: 10.1164/rccm.200604-571ST.

Hinks TS, Wallington JC, Williams AP, Djukanović R, Staples KJ, Wilkinson TM (2016). Steroid-induced deficiency of mucosal-associated invariant $\mathrm{T}$ cells in the chronic obstructive pulmonary disease lung implications for nontypeable haemophilus influenzae infection. American Journal of Respiratory and Critical Care Medicine, 194(10): 12081218. doi: 10.1164/rccm.201601-OOO$2 \mathrm{OC}$.

Hirose W, Harigai M, Uchiyama T, Itoh K, Ishizuka T, Matsumoto M, Nanki T (2019). Low body mass index and lymphocytopenia associate with Mycobacterium avium complex pulmonary disease in patients with rheumatoid arthritis. Modern Rheumatology, 29(1): 
Saptawati et al./Risk Factors and Prognosis of Nontuberculous Mycobacteria Infection

105-112. https://doi.org/10.1080/14397595.2018.1452334

Johnson MM, Odell JA (2014). Nontuberculous mycobacterial pulmonary infections. J Thorac Dis. 6(3): 210-20. doi: 10.3978/j.issn.2072-1439.2013.12.24.

Juita LR, Fauzar (2018). Diagnosis dan tatalaksana penyakit paru nontuberculous (Diagnosis and management of nontuberculous lung disease). Jurnal Kesehatan Andalas. 7(3): 141-145. Doi: https://doi.org/10.25077/jka.v7.io.p141-145.2018.

Lee H, Myung W, Koh WJ, Moon SM, Jhun BW (2019). Epidemiology of Nontuberculous Mycobacterial Infection, South Korea, 2007-2016. Emerging infectious diseases, 25(3): 569-572. doi: 10.3201/eid2503.181597.

Lim AYH, Chotirmall SH, Fok ETK, Verma A, De PP, Goh SK, Puah SH, Goh DEL, Abisheganaden JA (2018). Profiling non-tuberculous mycobacteria in an Asian setting: Characteristics and clinical outcomes of hospitalized patients in Singapore. BMC Pulmonary Medicine. 18(1): 1-7. doi: 10.1186/s12890018-0637-1.

Maekawa K, Ito Y, Hirai T, Kubo T, Imai S, Tatsumi S, Fujita K, Takakura S, et al. (2011). Environmental risk factors for pulmonary Mycobacterium aviumintracellulare complex disease. Chest. 140(3): 723-729. doi: 10.1378/chest.10-2315.
Marras TK, Campitelli MA, Kwong JC, Lu H, Brode SK, Marchand-Austin A, Gershon AS, Jamieson FB (2016). Risk of nontuberculous mycobacterial pulmonary disease with obstructive lung disease. European Respiratory Journal, 48(3): 928-931. doi: 10.1183/13993003.00033-2016.

Namkoong H, Kurashima A, Morimoto K, Hoshino Y, Hasegawa N, Ato M, Mitarai $S$ (2016). Epidemiology of pulmonary Nontuberculous mycobacterial disease, Japan. Emerging Infectious Diseases, 22(6): 1116-1117. doi: 10.3201/eid2206.151086.

Patterson CM, Morrison RL, D'Souza A, Teng XS, Happel KI (2012). Inhaled fluticasone propionate impairs pulmonary clearance of Klebsiella Pneumoniae in mice. Respiratory Research. 13(1): 40. doi: 10.1186/1465-9921-13-40.

Saptawati L, Kusumo H, Suryawati B (2019). Prevalence of Non-tuberculous Mycobacteria (NTM) in Surakarta, Indonesia: Higher Than Expected. The 1st International Conference on Health, Technology and Life Sciences. 132-138. doi: 10.18502/kls.v4i12.4166.

Stout JE, Koh WJ, Yew WW (2016). Update on pulmonary disease due to non-tuberculous mycobacteria. International Journal of Infectious Diseases. International Society for Infectious Diseases, 45: 123-134. doi: 10.1016/j.ijid.2016.03.006. 